\title{
Effects of patient health literacy, patient engagement and a system-level health literacy attribute on patient-reported outcomes: a representative statewide survey
}

\author{
Kimberly A Kaphingst ${ }^{1,2^{*}}$, Nancy L Weaver ${ }^{3}$, Ricardo J Wray ${ }^{3}$, Melissa LR Brown ${ }^{1}$, Trent Buskirk
} and Matthew W Kreuter ${ }^{1}$

\begin{abstract}
Background: The effects of health literacy are thought to be based on interactions between patients' skill levels and health care system demands. Little health literacy research has focused on attributes of health care organizations. We examined whether the attribute of individuals' experiences with front desk staff, patient engagement through bringing questions to a doctor visit, and health literacy skills were related to two patient-reported outcomes.

Methods: We administered a telephone survey with two sampling frames (i.e., household landline, cell phone numbers) to a randomly selected statewide sample of 3358 English-speaking adult residents of Missouri. We examined two patient-reported outcomes - whether or not respondents reported knowing more about their health and made better choices about their health following their last doctor visit. Multivariable logistic regression models were used to examine the independent contributions of predictor variables (i.e., front desk staff, bringing questions to a doctor visit, health literacy skills).
\end{abstract}

Results: Controlling for self-reported health, having a personal doctor, time since last visit, number of chronic conditions, health insurance, and sociodemographic characteristics, respondents who had a good front desk experience were 2.65 times as likely $(95 \%$ confidence interval $[\mathrm{Cl}]: 2.13,3.30$ ) and those who brought questions were 1.73 times as likely ( $95 \% \mathrm{Cl}: 1.32,2.27)$ to report knowing more about their health after seeing a doctor. In a second model, respondents who had a good front desk experience were 1.57 times as likely $(95 \% \mathrm{Cl}: 1.26,1.95)$ and those who brought questions were 1.66 times as likely $(95 \% \mathrm{Cl}: 1.29,2.14)$ to report making better choices about their health after seeing a doctor. Patients' health literacy skills were not associated with either outcome.

Conclusions: Results from this representative statewide survey may indicate that one attribute of a health care organization (i.e., having a respectful workforce) and patient engagement through question asking may be more important to patient knowledge and health behaviors than patients' health literacy skills. Findings support focused research to examine the effects of organizational attributes on patient health outcomes and system-level interventions that might enhance patient health.

Keywords: Health literacy, Organizational attributes, Patient engagement, Health literate organizations

\footnotetext{
* Correspondence: kaphingstk@wudosis.wustl.edu

${ }^{1}$ Health Communication Research Laboratory, Washington University, St. Louis, MO, USA

${ }^{2}$ Division of Public Health Sciences, Department of Surgery, Washington University School of Medicine, Campus Box 8100, 660 S. Euclid Ave, St. Louis, MO 63110, USA

Full list of author information is available at the end of the article
} 


\section{Background}

Research has demonstrated the critical relationships between patient health literacy and incidence of chronic disease, self-reported health, utilization of preventive health services, health knowledge, rates of hospitalization, and health care costs [1-5]. The effects of health literacy are thought to be based on interactions between patients' skill levels and the demands of health care and social systems [3]. To date, patients' skills have received more attention in health literacy research and practice than have attributes of health care organizations. However, a recent report from the Institute of Medicine Roundtable on Health Literacy [6] and federal policy initiatives $[7,8]$ have drawn new attention to the attributes of health literate health care organizations (i.e., organizations that make it easier for people to navigate, understand, and use information and services to take care of their health) [6]. Little research has compared the relative importance of patients' health literacy skills and organizational attributes, such as having a respectful health care environment and quality providerpatient communication, in determining patient-reported outcomes of care.

Patients' interactions with health care staff are important to patient outcomes $[9,10]$ and having a respectful workforce that avoids stigmatizing patients with limited health literacy is a key attribute of health literate health care organizations [6]. Ethnographic research has shown the important role receptionists play in quality and safety of repeat prescribing of medications in general practice [11], and an intervention study examined the effects of training office staff about health literacy on staff knowledge and intentions [12]. However, little is known about the importance of front desk staff as part of a health literate workforce.

The quality of provider-patient communication is another attribute of health literate health care organizations suggested to affect patient outcomes [6,13-16]. In particular, patient engagement through question asking can enhance satisfaction and recall of information imparted during an office visit [17], and research has shown that interventions that improve patients' question asking can increase adherence to treatment recommendations and other medical outcomes [15,18-21]. The importance of patient engagement and question asking has also been emphasized in health literacy practice [22-24]. Previous research has shown that patient engagement and activation influence different health outcomes than individual health literacy skills $[25,26]$. Despite this prior work, the relative importance of patient health literacy skills compared with health literacy-related attributes of organizations, such as having a respectful workforce, and patient engagement through question asking has not been investigated.

We examined this question using data from a representative statewide telephone survey of Missouri residents. We examined the extent to which respondents' experiences with front desk staff, bringing questions to a doctor visit, or their health literacy skills were predictive of two patient-reported outcomes - whether or not respondents learned from a medical encounter and whether or not they made better choices about their health following that encounter. We hypothesized that respondents who had better experiences with front desk staff, who brought questions to their providers, and who had higher health literacy skills would report learning more from and making better choices following a doctor visit.

\section{Methods \\ Sample}

We administered a telephone survey to a statewide sample of Missouri residents using two sampling frames: household landline telephone numbers within area codes in Missouri and cell phone numbers covering the same area. Primary sampling units (PSUs) included the 115 counties within Missouri and secondary sampling units (SSUs) included landline and cell phone numbers within each county. We used a two-stage probability sampling design that first selected a sample of PSUs and then selected a sample of SSUs from each PSU. We used a screener to identify cell phone-only households, which tend to be younger, more transient, and from racial and ethnic minority groups [27]. One member of each sampled household was systematically selected to complete the telephone survey. We oversampled four counties previously identified as having a greater proportion of residents with limited health literacy [28]. Inclusion criteria included being age 18 or older, speaking English, and having a landline telephone or cell phone. Excluding disconnected numbers, business and fax numbers, the participation rate was $42 \%$. Respondents received a \$15 incentive for participation. This study was approved by the Washington University Institutional Review Board.

\section{Measures}

The survey was developed based on a review of existing health literacy measures and related patient care constructs. We identified measures from multiple sources and adapted them for telephone administration in a general population sample [29-33]. The survey was reviewed during its development by a multi-institutional advisory board comprised of primary care physicians, health literacy practitioners, and health communication experts.

We assessed patient-reported outcomes related to their last doctor visit with two items: "After going to the doctor, do you feel like you know more about your health?" and "After going to the doctor, do you feel like you are making better choices about your health?" [yes, no, don't know/not sure]. 
We assessed three possible predictor variables (i.e., front desk experience, patient engagement through question asking, patient health literacy). To assess front desk experience at their last doctor visit, we asked patients "Did the staff at the front desk make you feel comfortable?" [not at all, somewhat, very comfortable] and "Did the staff at the front desk treat you with respect?" [little or no, some, great respect]. We examined patient engagement through question asking at last doctor visit using the item: "Did you take a list of questions to ask the doctor?" [yes, no, don't know/not sure]. Because this was a telephone survey, health literacy was assessed using one self-report item: "How confident are you filling out medical forms by yourself?" [not at all, somewhat, extremely confident; [34]]. This screener item has been validated against objective measures of health literacy including the S-TOFHLA [35] and REALM [36,37], which require in-person administration.

We also assessed a number of sociodemographic and self-reported health covariates. Respondents answered items on self-reported health [38], having a personal doctor, time since last doctor visit, having any form of health care coverage, educational attainment, gender, race and ethnicity, age, and personal diagnosis with diabetes, asthma, high blood pressure, high cholesterol, depression, or cancer.

\section{Analysis}

Sampling weights were generated by first computing base weights based on the fact that for each county, simple random samples of phone numbers were selected from each of two overlapping frames - landline and cell phone. Weights then accounted for nonresponse for each frame and were calibrated to marginal state totals for control variables (i.e., age, sex, race, education, county) that were hypothesized to be associated with key outcomes of interest. The final computed weights were applied to all analyses in order to reflect population distributions. The self-reported health of the sample was very similar to the Missouri population as described by the Missouri Behavioral Risk Factor Surveillance System [38], and the gender, race, and health insurance distributions for our sample did not differ significantly from that of Census data for the state [39].

Descriptive statistics were examined for all variables. Bivariate analyses using chi-squared tests were conducted to examine the associations between outcome (i.e., reporting knowing more about health and making better choices about health after seeing doctor) and predictor (i.e., front desk experience, bringing questions to visit, health literacy skills) variables. We then built multivariable logistic regression models to examine the independent contributions of the predictor variables. In these models, outcomes were dichotomized as yes vs. no/don't know. Because of the high correlation between the two front desk experience variables, we created a summed score; "good front desk experience" was defined as those who felt very comfortable with front desk staff and felt that front desk staff treated them with great respect. We also tested pairwise interactions to examine whether patients' health literacy skills modified the associations of front desk experience and bringing questions with the outcome variables. Covariates tested in the multivariable models were: number of diagnosed chronic diseases (continuous); self-reported health (very good/excellent vs. good/fair/ poor); having a personal doctor (yes vs. no/don't know); last time saw doctor (less than 12 months ago vs. other); having health care coverage (any vs. none); educational attainment (less than high school; high school degree/GED; some college/technical degree; college degree or higher); gender; race/ethnicity (White, Black, other categories); and age (continuous). Observations missing values for a variable were not included in analyses using that variable. Data were analyzed using SAS Version 9.3 (Cary, NC). Statistical significance was assessed as $\mathrm{p}<0.05$.

\section{Results}

Most respondents to the statewide survey were White (85\%), and had some form of health insurance (82\%), a personal doctor (77\%), seen a doctor within the last 12 months $(86 \%)$ and some education beyond high school (58\%). Half were women (52\%) and the mean age was 47 years (Table 1).

\section{Knowing more about health after seeing doctor}

In bivariate analysis (Table 2), both of the front desk experience variables were significantly related to the outcome variable of respondents reporting that they knew more about their health after seeing a doctor $(\mathrm{p}<.0001)$, as was the combined front desk experience variable $(\mathrm{p}<.0001)$. In addition, respondents who brought questions to the visit $(\mathrm{p}<.0001)$ reported knowing more after the visit than those who did not. Respondents' health literacy skills were not related to reporting knowing more after the visit.

In a multivariable logistic regression model, having a good front desk experience and bringing questions were significant independent predictors of knowing more about health after a doctor visit (Table 3). Respondents who had a good front desk experience were 2.65 times as likely (95\% confidence interval $[\mathrm{CI}]: 2.13,3.30$ ) to report knowing more about their health after seeing the doctor. Respondents who brought questions to the visit were 1.73 times as likely $(95 \%$ CI: $1.32,2.28)$ to report knowing more. Patient health literacy skill was not a significant predictor or moderator of this outcome.

In this model, self-reported health, having a personal doctor, and race/ethnicity were significant covariates. 
Table 1 Characteristics of statewide sample of adult Missouri residents $(\mathrm{N}=\mathbf{3 3 5 8})$

\begin{tabular}{|c|c|c|}
\hline Variable & $\mathbf{N}$ & $\%$ \\
\hline \multicolumn{3}{|l|}{ Health status } \\
\hline Excellent & 510 & 15.2 \\
\hline Very good & 1143 & 34.1 \\
\hline Good & 1061 & 31.6 \\
\hline Fair & 464 & 13.9 \\
\hline Poor & 175 & 5.2 \\
\hline \multicolumn{3}{|l|}{ Number of chronic diseases } \\
\hline 0 & 1304 & 38.9 \\
\hline 1 & 919 & 27.4 \\
\hline $2-3$ & 994 & 29.6 \\
\hline $4-6$ & 138 & 4.1 \\
\hline Have personal doctor & 2564 & 76.5 \\
\hline Last doctor visit less than 12 months ago & 2871 & 85.5 \\
\hline Have private or public health insurance & 2736 & 81.8 \\
\hline Female & 1745 & 52.0 \\
\hline \multicolumn{3}{|l|}{ Educational attainment } \\
\hline Less than high school & 395 & 11.8 \\
\hline High school/GED & 1005 & 30.0 \\
\hline Some college/Technical degree & 1204 & 35.9 \\
\hline College degree or higher & 748 & 22.3 \\
\hline \multicolumn{3}{|l|}{ Race/ethnicity } \\
\hline White & 2844 & 84.8 \\
\hline Black/African American & 373 & 11.1 \\
\hline Hispanic/Latino & 28 & 0.8 \\
\hline Asian American & 39 & 0.2 \\
\hline American Indian/Alaska Native & 47 & 1.4 \\
\hline Other & 22 & 0.7 \\
\hline \multicolumn{3}{|l|}{ Health literacy ${ }^{*}$} \\
\hline Not at all confident & 172 & 5.3 \\
\hline Somewhat confident & 1272 & 38.2 \\
\hline \multirow[t]{2}{*}{ Extremely confident } & 1885 & 56.6 \\
\hline & M & SD \\
\hline Age & 47 & 17.9 \\
\hline
\end{tabular}

*Health literacy was assessed using the screener item "How confident are you filling out medical forms by yourself? ${ }^{\prime \prime 34}$.

Respondents with very good or excellent health were more likely to report knowing more about health after a doctor visit than those with good, fair or poor health (odds ratio [OR]: 1.49; 95\% CI: 1.19, 1.87), as were those with a personal doctor (OR: 1.83; 95\% CI: 1.42, 2.37) compared to those without one. Compared with White respondents, those who identified as Black or African American (OR: 1.56; 95\% CI: 1.09, 2.22) and those from another racial or ethnic group (OR: 1.88; 95\% CI: 1.04 ,
3.40) were more likely to report knowing more about health after a doctor visit.

\section{Making better choices about health after seeing doctor}

In bivariate analysis, both front desk experience variables were significantly related to the outcome variable of respondents reporting that they made better choices about their health after seeing a doctor $(\mathrm{p}<.0001)$, as was the combined front desk experience variable $(\mathrm{p}<.0001)$. Respondents who brought questions to the visit $(\mathrm{p}<.0001)$ also reported making better choices after the visit. Respondents' health literacy skills were not related to reporting making better choices after the visit.

In a multivariable model, having a good front desk experience and bringing questions to the visit were significant independent predictors of making better choices after a doctor visit (Table 4). Respondents who had a good front desk experience were 1.57 times as likely (95\% CI: 1.26, 1.95) to report making better choices about their health after seeing a doctor. Respondents who brought questions to the visit were 1.66 times as likely (95\% CI: 1.29, 2.14) to report making better health choices after a visit. Patient health literacy skill was not a significant predictor or moderator of this outcome.

In this multivariable model, having a personal doctor, having seen a doctor within the last 12 months, educational attainment, and race/ethnicity were significant covariates. Respondents with a personal doctor were more likely (OR: 1.94; 95\% CI: 1.52, 2.47) to report making better choices about their health after a visit than those without one. Those who had seen a doctor within the past 12 months were also more likely to report making better choices (OR: 1.57, 95\% CI: 1.22, 2.01). Compared with those who had not completed high school, respondents with some college or a technical degree (OR: 0.59; 95\% CI: 0.41, 0.86) and with at least a college degree (OR: 0.53 ; $95 \%$ CI: $0.36,0.79$ ) were less likely to report making better choices about their health after a doctor visit. Respondents who identified as Black or African American were more likely (OR: 2.70; 95\% CI: $1.81,4.02)$ to report making better health choices after a visit compared with White respondents.

\section{Discussion}

The results of this representative statewide survey of Missouri adults may indicate that one attribute of a health care organization (i.e., having a respectful workforce) and patient engagement through question asking may be more important to patient knowledge and health behaviors than patients' health literacy skills. We found that those who had a good front desk experience and brought questions to a doctor visit were more likely to report learning from and making better choices following the visit than their counterparts. In contrast, patients' health literacy skills 
Table 2 Bivariate associations between patients' front desk experience, question behavior, and health literacy skills, and patient-reported outcomes of care $(\mathrm{N}=3358)$

\begin{tabular}{|c|c|c|c|c|}
\hline \multirow[b]{3}{*}{ Variable } & \multicolumn{4}{|c|}{ Patient-reported outcomes } \\
\hline & \multicolumn{2}{|c|}{ Know more about health after seeing doctor } & \multicolumn{2}{|c|}{ Make better choices about health after seeing docto } \\
\hline & N (\%) & p-value & N (\%) & p-value \\
\hline \multicolumn{5}{|l|}{ Front desk experience } \\
\hline Comfort with front desk staff & & $<0.0001$ & & $<0.0001$ \\
\hline Very comfortable & $1963(89.6 \%)$ & & $1858(85.9 \%)$ & \\
\hline Somewhat comfortable & $742(77.8 \%)$ & & $730(78.4 \%)$ & \\
\hline Not at all comfortable & $55(53.3 \%)$ & & $57(56.2 \%)$ & \\
\hline Treated with respect by front desk staff & & $<0.0001$ & & $<0.0001$ \\
\hline Great respect & $2035(88.9 \%)$ & & $1912(84.7 \%)$ & \\
\hline Some respect & $669(77.4 \%)$ & & $671(79.1 \%)$ & \\
\hline Little or no respect & $55(57.6 \%)$ & & $61(64.6 \%)$ & \\
\hline Front desk experience & & $<0.0001$ & & $<0.0001$ \\
\hline Good front desk experience & $2266(88.3 \%)$ & & $2143(84.8 \%)$ & \\
\hline Poor front desk experience & 499 (72.2\%) & & $506(74.6 \%)$ & \\
\hline \multicolumn{5}{|l|}{ Patient question behaviors } \\
\hline Brought questions to visit & & $<0.0001$ & & $<0.0001$ \\
\hline Yes & $700(90.1 \%)$ & & $671(88.2 \%)$ & \\
\hline No & $2073(83.3 \%)$ & & $1978(80.6 \%)$ & \\
\hline Patient health literacy skills ${ }^{*}$ & & 0.13 & & 0.23 \\
\hline Extremely confident & $1588(86.1 \%)$ & & $1503(82.2 \%)$ & \\
\hline Somewhat confident & $1045(83.7 \%)$ & & $1016(83.3 \%)$ & \\
\hline Not at all confident & 135 (82.5\%) & & $124(77.9 \%)$ & \\
\hline
\end{tabular}

were not significantly related to either outcome, and this variable did not moderate the observed associations. The finding that at least one aspect of the health literacy demands of a health care setting may affect patients' experiences more than their own skills suggests that creating a health literate health care organization that can respond effectively to the needs of all patients may be more critical than interventions to improve the health literacy skills of individual patients.

Front office staff have been described as the face of a health care setting, shaping patients' first and last impressions of the organization [40]. These staff members have many important roles, including helping patients access care, complete medical and insurance forms, make appointments, and obtain prescriptions. Some attention has been given to the importance of training staff in communication skills [41,42], although few studies have focused specifically on training staff in organizational attributes important to health literacy, such as the creation of a respectful and shame-free environment $[6,12,23]$. Our findings support the importance of respondents' interactions with front desk staff as being significantly related to patient-reported outcomes of care. An important next step is to examine what types of interactions are driving responses to these variables; for example, whether responses are related to specific interactions with different types of front desk staff, frustration with the larger health care system, or a combination.

One mechanism by which interactions with front desk staff might impact patient outcomes is suggested by the finding that having a good front desk experience was a stronger predictor of reporting learning from a doctor visit than reporting making better choices after the visit. A possible explanation for this finding is that a person's emotional response to a negative front desk experience might adversely affect their ability or motivation to process information in a doctor's visit occurring only minutes later. Functional emotion theories posit that different emotions have different effects in generating, sustaining, and focusing a person's cognitive activity [43]. Anger is generally evoked when obstacles interfere with goal-oriented behavior or one experiences demeaning offenses against oneself or one's loved ones [44,45], which could result from an unpleasant experience with front desk staff. This type of emotional reactance (i.e., unexpected, unintended anger) 
Table 3 Predictors of knowing more about health after seeing a doctor in a multivariable logistic regression model $(\mathrm{N}=3202)$

\begin{tabular}{|c|c|c|}
\hline Variable & $\begin{array}{l}\text { Odds } \\
\text { ratio }\end{array}$ & $\begin{array}{l}95 \% \text { confidence } \\
\text { interval }\end{array}$ \\
\hline \multicolumn{3}{|l|}{ Predictor variables } \\
\hline Good front desk experience & 2.65 & $2.13,3.30^{l l}$ \\
\hline Brought questions to visit & 1.73 & $1.32,2.27^{\|}$ \\
\hline \multicolumn{3}{|l|}{ Health literacy* } \\
\hline Extremely confident & 0.97 & $0.61,1.55$ \\
\hline Somewhat confident & 0.91 & $0.57,1.45$ \\
\hline \multicolumn{3}{|l|}{ Health-related covariates } \\
\hline Very good or excellent health ${ }^{\dagger}$ & 1.49 & $1.19,1.87^{\natural}$ \\
\hline Have personal doctor & 1.83 & $1.42,2.37^{\|}$ \\
\hline Having seen doctor in last 12 months & 1.26 & $0.96,1.65$ \\
\hline Number of chronic diseases & 1.01 & $0.92,1.12$ \\
\hline Having any medical coverage & 1.00 & $0.76,1.33$ \\
\hline \multicolumn{3}{|l|}{ Sociodemographic covariates } \\
\hline \multicolumn{3}{|l|}{ Educational attainment $^{\ddagger}$} \\
\hline High school/GED & 0.94 & $0.65,1.36$ \\
\hline Some college/Technical degree & 0.71 & $0.49,1.02$ \\
\hline College degree or higher & 0.69 & $0.46,1.03$ \\
\hline Female & 1.11 & $0.90,1.36$ \\
\hline Age & 1.00 & $0.99,1.01$ \\
\hline \multicolumn{3}{|l|}{ Race/ethnicity ${ }^{\S}$} \\
\hline Black & 1.56 & $1.09,2.22^{\#}$ \\
\hline Other & 1.88 & $1.04,3.40^{\#}$ \\
\hline
\end{tabular}

*Referent category is not at all confident.

${ }^{\dagger}$ Referent category is good, fair, or poor self-reported health.

${ }^{\ddagger}$ Referent category is less than high school.

${ }^{5}$ Referent category is White.

$\|_{p}<0.001$

${ }^{\mathrm{p}} \mathrm{p}<0.01$.

$\# p<0.05$.

could interfere with or generate resistance to information from an affiliated source (e.g., a health care provider) $[43,46]$.

Our results also highlighted the importance of patient engagement in the medical encounter through bringing questions to the visit. While some low-intensity interventions to encourage patient question asking have not affected patient behaviors [22], other studies have shown that patient question asking can affect patient knowledge, satisfaction, adherence, and the quality of provider-patient interactions $[19,20,47]$. Because patients with limited health literacy have a complex array of communication challenges [48], which could impact their interactions with providers [22,49-51], we tested for an interaction between bringing questions to the visit and patients' health literacy skills. The lack of a significant interaction suggests that patient engagement through question asking is important for patients
Table 4 Predictors of making better choices about health after seeing a doctor in a multivariable logistic regression model $(\mathrm{N}=3134)$

\begin{tabular}{|c|c|c|}
\hline Variable & $\begin{array}{l}\text { Odds } \\
\text { ratio }\end{array}$ & $\begin{array}{c}95 \% \text { confidence } \\
\text { interval }\end{array}$ \\
\hline \multicolumn{3}{|l|}{ Predictor variables } \\
\hline Good front desk experience & 1.57 & $1.26,1.95^{\|}$ \\
\hline Brought questions to visit & 1.66 & $1.29,2.14^{\|}$ \\
\hline \multicolumn{3}{|l|}{ Health literacy* } \\
\hline Extremely confident & 1.07 & $0.68,1.66$ \\
\hline Somewhat confident & 1.22 & $0.78,1.90$ \\
\hline \multicolumn{3}{|l|}{ Health-related covariates } \\
\hline Very good or excellent health ${ }^{\dagger}$ & 1.05 & $0.85,1.30$ \\
\hline Have personal doctor & 1.94 & $1.52,2.4711$ \\
\hline Having seen doctor in last 12 months & 1.57 & $1.22,2.01^{\natural}$ \\
\hline Number of chronic diseases & 0.98 & $0.89,1.08$ \\
\hline Having any medical coverage & 1.00 & $0.77,1.31$ \\
\hline \multicolumn{3}{|l|}{ Sociodemographic covariates } \\
\hline \multicolumn{3}{|l|}{ Educational attainment $^{\ddagger}$} \\
\hline High school/GED & 0.83 & $0.57,1.20$ \\
\hline Some college/Technical degree & 0.59 & $0.41,0.86^{\mathbb{q}}$ \\
\hline College degree or higher & 0.53 & $0.36,0.79$ \\
\hline Female & 1.14 & $0.93,1.38$ \\
\hline Age & 1.01 & $0.99,1.01$ \\
\hline \multicolumn{3}{|l|}{ Race/ethnicity ${ }^{\S}$} \\
\hline Black & 2.70 & $1.81,4.02^{11}$ \\
\hline Other & 1.19 & $0.74,1.92$ \\
\hline
\end{tabular}

*Referent category is not at all confident.

${ }^{\dagger}$ Referent category is good, fair, or poor self-reported health.

${ }^{\ddagger}$ Referent category is less than high school.

${ }^{\S}$ Referent category is White.

$\|_{\mathrm{p}}<0.001$

${ }^{\mathrm{p}} \mathrm{p}<0.01$.

with varying levels of health literacy skills. This finding therefore supports a universal approach of encouraging all patients, not just those with limited health literacy skills, to bring questions to doctor visits [23,24].

This study had a number of limitations. The telephone survey was cross-sectional, so we could not investigate direction of causality and prospective study designs are needed in order to examine these associations further. Respondents were asked to think about their last doctor visit in answering questions, and unpleasant or uncomfortable experiences may be more vivid in memories, leading to recall bias. Because the attributes of health literate health care organizations are a new area of inquiry, we did not find validated survey items in our literature review and we therefore adapted the items used here from existing related measures. The survey items were assessed for content validity by a transdisciplinary group of health care providers, researchers, and practitioners, but we 
did not further validate the items with a population-based sample. Therefore, although the patient-reported outcomes reflect patients' experiences, they may differ from objective measures of improvement in comprehension or health behaviors following a doctor visit. Furthermore, the front desk experience variable captures only one aspect of the attributes of a health literate health care organization. Validated measures are greatly needed to advance inquiry regarding the effects of various attributes of health care organizations on health literacy outlined by the Institute of Medicine [6].

In addition, to limit participant burden and because of the time constraints of the telephone survey, we had only a limited number of questions for each construct. For example, we asked about front desk staff generally rather than specific roles, and it is not clear whether patients differentiated between different types of front desk staff. The identified associations between front desk experience and patient-reported outcomes should be investigated in greater depth in a future study. Finally, we used a self-report item to assess respondents' health literacy skills and respondents may have overestimated their skill levels. Although this item has been validated against standard measures of health literacy skills $[34,52]$, it will be important to explore these results further with other measures of functional health literacy.

\section{Conclusions}

Despite these limitations, the results of this representative statewide survey of Missouri adults highlights an important and novel area that has not generally been a focus of health literacy research, that at least some health literacy attributes of a health care organization and patient engagement may be more important to patient knowledge and health behaviors than the health literacy skills of individual patients. Much of the focus in health literacy research has been to examine the associations between individual-level patient skills and various health outcomes. These findings speak to the importance of expanding the focus of health literacy to examine the effects of attributes of health care organizations on patient outcomes and investigating how system-level interventions to improve health literacy organizational attributes and to encourage patient engagement can enhance patient health.

\section{Competing interests}

Dr. Buskirk is currently employed by Marketing Systems Group. The other authors declare that they have no competing interests.

\section{Authors' contributions}

KAK, NLW, RJW, TB, MLRB, and MWK participated in the design of the study and analytic plan and interpretation of findings. KAK drafted the manuscript. NLW, RJW, TB, MLRB, and MWK developed data collection processes.

All authors read and approved the manuscript.

\section{Acknowledgements}

This research was supported by a contract from the Missouri Foundation for Health and by funding by the Barnes-Jewish Hospital Foundation. The funding bodies had no role in the collection, analysis, or interpretation of data or in the preparation and submission of the manuscript. We thank Choi Lai for her assistance with data analysis and the health literacy grantees and affiliated program staff from the Missouri Foundation for Health and the Community Advisory Network members for providing feedback during the survey development process.

\section{Author details}

${ }^{1}$ Health Communication Research Laboratory, Washington University, St. Louis, MO, USA. ${ }^{2}$ Division of Public Health Sciences, Department of Surgery, Washington University School of Medicine, Campus Box 8100, 660 S. Euclid Ave, St. Louis, MO 63110, USA. ${ }^{3}$ Saint Louis University School of Public Health, St. Louis, MO, USA.

Received: 22 July 2014 Accepted: 29 September 2014 Published: 7 October 2014

\section{References}

1. Berkman N, Pignone MP, DeWalt D, Sheridan S: Health Literacy: Impact on Health Outcomes. Rockville, MD: Agency for Healthcare Research and Quality; 2004.

2. Gazmararian JA, Williams M, Peel J, Baker D: Health literacy and knowledge of chronic disease. Patient Educ Couns 2003, 51:267-275.

3. Nielsen-Bohlman L, Panzer AM, Kindig DA (Eds): Health Literacy: A Prescription to End Confusion. Washington, DC: National Academies Press; 2004.

4. Gazmararian JA, Baker DW, Williams MV, Parker R, Scott TL, Green DC, Fehrenbach SN, Ren J, Koplan JP: Health literacy among Medicare enrollees in a managed care organization. JAMA 1999, 281(6):545-551.

5. Berkman N, Sheridan S, Donahue K, Halpern DJ, Viera A, Crotty K, Holland A, Brasure M, Lohr KN, Harden E, Tant E, Wallace I, Viswanathan M: Health Literacy Interventions and Outcomes: An Updated Systematic Review, Evidence Report/Technology Assessment No 1999. Rockville, MD: Agency for Healthcare Research and Quality; 2011.

6. Brach C, Keller D, Hernandez LM, Baur C, Parker R, Dreyer B, Schyve $P$, Lemerise A, Schillinger D: Ten Attributes of Health Literate Health Care Organizations. Washington, DC: Institute of Medicine of the National Academies; 2012.

7. Koh HK, Berwick DM, Clancy CM, Baur C, Brach C, Harris LM, Zerhusen EG: New federal policy initiatives to boost health literacy can help the nation move beyond the cycle of costly 'crisis care'. Health Aff (Millwood) 2012, 31(2):434-443.

8. Koh HK, Brach C, Harris LM, Parchman ML: A proposed 'health literate care model' would constitute a systems approach to improving patients' engagement in care. Health Aff (Millwood) 2013, 32(2):357-367.

9. Redling R: Improving customer service. It's not just what's in the box. MCMA Connex 2003, 3(7):36-41.

10. Brand R, Cronin J, Routledge J: Marketing to older patients: perceptions of service quality. Health Mark Q 1997, 15(2):1-31.

11. Swinglehurst D, Greenhalgh T, Russell J, Myall M: Receptionist input to quality and safety in repeat prescribing in UK general practice: ethnographic case study. BMJ 2011, 343:d6788.

12. Mackert M, Ball J, Lopez N: Health literacy awareness training for healthcare workers: improving knowledge and intentions to use clear communication techniques. Patient Educ Couns 2011, 85(3):e225-e228.

13. Stewart M: Effective physician-patient communication and health outcomes: a review. CMAJ 1995, 152(9):1423-1433.

14. Stewart M, Brown J, Boon H, Galajda J, Meredith L, Sangster M: Evidence on patient-doctor communication. Cancer Prev Control 1999, 3(1):25-30.

15. Kaplan S, Greenfield S, Ware J Jr: Assessing the effects of physician-patient interactions on the outcomes of chronic disease. Med Care 1989, 27(3 Suppl):S110-S127.

16. Schillinger D, Piette J, Grumbach K, Wang F, Wilson C, Daher C, Leong-Grotz K, Castro C, Bindman AB: Closing the loop: physician communication with diabetic patients who have low health literacy. Arch Intern Med 2003, 163:83-90.

17. Thompson SC, Nanni C, Schwankovsky L: Patient-oriented interventions to improve communication in a medical office visit. Health Psychol 1990, 9(4):390-404. 
18. Post $D$, Cegala $D$, Wiser $W$ : The other half of the whole: teaching patients to communicate with physicians. Fam Med 2002, 34(5):344-352.

19. Cegala D, Marinelli T, Post D: The effects of patient communication skills training on compliance. Arch Fam Med 2000, 9(1):57-64.

20. Roter D: Patient participation in the patient-provider interaction: the effects of patient question asking on the quality of interaction, satisfaction, and compliance. Health Educ Monogr 1977, 5(4):281-315.

21. Butow P, Dunn S, Tattersall M, Jones Q: Patient participation in the cancer consultation: evaluation of a question prompt sheet. Ann Oncol 1994, 5(3):199-204.

22. Galliher JM, Post DM, Weiss BD, Dickinson LM, Manning BK, Staton EW, Brown JB, Hickner JM, Bonham AJ, Ryan BL, Pace WD: Patients' question-asking behavior during primary care visits: a report from the AAFP National Research Network. Ann Fam Med 2010, 8:151-159.

23. Weiss B: Health Literacy and Patient Safety: Help Patients Understand. Chicago, IL: American Medical Association Foundation; 2007.

24. Agency for Healthcare Research and Quality: Health literacy universal precautions toolkit. 2010, [http://www.ahrq.gov/qual/literacy/index.html] Accessed 5/31/14.

25. Greene J, Hibbard J, Tusler M: How Much Do Health Literacy and Patient Activation Contribute to Older Adults' Ability to Manage Their Health? Washington, DC: AARP Public Policy Institute; 2005.

26. Smith $\mathrm{S}$, Curtis L, Wardle J, von Wagner C, Wolf M: Skill set or mind set? Associations between health literacy, patient activation and health. PLoS One 2013, 8(9):e74373.

27. Blumberg S, Luke J: Wireless Substitution: Early Release of Estimates from the National Health Interview Survey, July-December 2008. Atlanta, GA: National Center for Health Statistics; 2009.

28. Lurie N, Martin LT, Ruder T, Escarce JJ, Ghosh-Dastidar B, Sherman D, Bird CE, Fremont A: Estimating and Mapping Health Literacy in the State of Missouri: RAND Working Paper. Santa Monica, CA: Rand; 2010.

29. Agency for Healthcare Research and Quality: CAHPS Clinician \& Group Survey. [https://cahps.ahrq.gov/surveys-guidance/cg/index.html] Accessed 06/03/14

30. Howie J, Heaney D, Maxwell M, Walker J: A comparison of a Patient Enablement Instrument (PEI) against two established satisfaction scales as an outcome measure of primary care consultations. Fam Pract 1998, 15(2):165-171.

31. Baker R: Development of a questionnaire to assess patients' satisfaction with consultations in general practice. Br J Gen Pract 1990, 40:487-490.

32. Seid M, Varni J, Bermudez L, Zivokic M, Davodi Far M, Nelson M, Kurtin PS: Parents' perceptions of primary care: measuring parents' experiences of pediatric primary care quality. Pediatrics 2001, 108(2):264-270.

33. Schinnow L: Literacy and Health Education. Marshalltown, IA: Iowa Valley Community College; 1990.

34. Chew LD, Griffin JM, Partin MR, Noorbaloochi S, Grill JP, Snyder A, Bradley KA, Nugent SM, Baines AD, VanRyn M: Validation of screening questions for limited health literacy in a large VA outpatient population. J Gen Intern Med 2008, 23(5):561-566.

35. Baker DW, Williams MV, Parker RM, Gazmararian JA, Nurss JR: Development of a brief test to measure functional health literacy. Patient Educ Couns 1999, 38:33-42.

36. Davis TC, Crouch MA, Long SW, Jackson RH, Bates P, George RB, Bairnsfather LE, Jackson RH, Bates P, George RB, Bairnsfather LE: Rapid assessment of literacy levels of adult primary care patients. Fam Med 1991, 23(6):433-435.

37. Davis TC, Long SW, Jackson RH, Mayeaux EJ, George RB, Murphy PW, Crouch MA: Rapid estimate of adult literacy in medicine: a shortened screening instrument. Fam Med 1993, 25:391-395.

38. Centers for Disease Control and Prevention: Behavioral risk factor surveillance system. [http://www.cdc.gov/brfss/] Accessed 5/31/14.

39. U.S. Census Bureau: State and county quick facts. [http://quickfacts.census. gov/afd/states/29/29189.html] Accessed 04/22/14.

40. Hadley H: Patient satisfaction in the patient-centered practice. Conn Med 2008, 72(5):313-314

41. Rowan K: Monthly communication skill coaching for healthcare staff. Patient Educ Couns 2008, 71(3):402-404.

42. Hart C, Drotar D, Gori A, Lewin L: Enhancing parent-provider communication in ambulatory pediatric practice. Patient Educ Couns 2006, 63(1-2):38-46.

43. Nabi R: Discrete emotions and persuasion. In The Persuasion Handbook: Developments in Theory and Practice. Edited by Dillard J, Pfau M. Thousand Oaks, CA: Sage; 2002:289-308.
44. Izard C: Human emotions. New York: Plenum Press; 1977.

45. Lazarus R: Emotion and Adaptation. New York: Oxford University Press; 1991.

46. Dillard J, Plotnick C, Godbold L, Freimuth V, Edgar T: The multiple affective outcomes of AIDS PSAs. Commun Res 1996, 23(1):44-72.

47. Lewis C, Pantell R, Sharp L: Increasing patient knowledge, satisfaction, and involvement: randomized trial of a communication intervention. Pediatrics 1991, 88(2):351-358.

48. Williams MV, Davis T, Parker RM, Weiss BD: The role of health literacy in patient-physician communication. Fam Med 2002, 34(5):383-389.

49. Schillinger D, Bindman A, Wang F, Stewart A, Piette J: Functional health literacy and the quality of physician-patient communication among diabetes patients. Patient Educ Couns 2004, 52:315-323.

50. Ishikawa $\mathrm{H}$, Yan E: The relationship of patient participation and diabetes outcomes for patients with high vs. low health literacy. Patient Educ Couns 2011, 84(6):393-397.

51. Katz M, Jacobson T, Veledar E, Kripalani S: Patient literacy and question-asking behavior during the medical encounter: a mixed-methods analysis. J Gen Intern Med 2007, 22(6):782-786.

52. Chew LD, Bradley KA, Boyko EJ: Brief questions to identify patients with with inadequate health literacy. Fam Med 2004, 36(8):588-594.

\section{doi:10.1186/1472-6963-14-475}

Cite this article as: Kaphingst et al: Effects of patient health literacy, patient engagement and a system-level health literacy attribute on patient-reported outcomes: a representative statewide survey. BMC Health Services Research 2014 14:475.

\section{Submit your next manuscript to BioMed Central and take full advantage of:}

- Convenient online submission

- Thorough peer review

- No space constraints or color figure charges

- Immediate publication on acceptance

- Inclusion in PubMed, CAS, Scopus and Google Scholar

- Research which is freely available for redistribution 